\title{
El conflicto social por el acceso al agua: poder y producción de piña en Costa Rica
}

\author{
Luis Bonilla-Bonilla* \\ https://orcid.org/0000-0001-5809-9806
}

Recibido: 15 de febrero de 2020 • Aceptado: 16 de junio de 2020

\section{Resumen}

La base de este artículo es una investigación realizada entre el 2017 y el 2018 desde la Cátedra de Sociología de la Escuela de Ciencias Sociales y Humanidades de la Universidad Estatal a Distancia (UNED). Uno de sus propósitos fue indagar dinámicas de conflicto sobre procesos de contaminación y acceso al agua potable en la zona atlántica y norte de Costa Rica, en determinados espacios territoriales en los cuales es notoria la interacción entre recurso hídrico, producción piñera y comunidades.

Palabras clave: Relaciones de poder, sujeto colectivo, movimiento socioambiental, recurso hídrico.

\footnotetext{
* Doctorado en Estudios Latinoamericanos con énfasis en Pensamiento Latinoamericano, de la Universidad Nacional de Costa Rica (UNA), Costa Rica. Bachiller y licenciado en Sociología, de la UNA. Profesor de la Escuela de Administración, de la UNA, Costa Rica. Profesor e investigador de la Cátedra de Sociología de la Facultad de Ciencias Sociales y Humanidades, Universidad Estatal a Distancia, de Costa Rica. Correo: luvibon9@gmail.com
} 


\title{
Social Conflict for Water Access: Power and Pineapple Production in Costa Rica
}

\begin{abstract}
This article is based on research conducted between 2017 and 2018 from the Chair of Sociology of the School of Social Sciences and Humanities from the State Distance University (UNED). One of its objectives was to explore conflict dynamics in pollution processes and access to safe drinking water in the Atlantic and Northern Zone of Costa Rica, in certain territorial spaces in which the interaction between water resources, pineapple production and communities is notorious.
\end{abstract}

Key words: Power relationships, collective subject, social-environmental movement, water resource.

\section{Le conflit social par l'accès à l'eau: Pouvoir et production de l'ananas au Costa Rica}

\section{Résumé}

Cet article a été élaboré à partir d'une recherche menée entre 2017 et 2018 par le Département de Sociologie de l'École de Sciences Sociales et Humanités de l'Université de l'État à Distance (UNED). L'un des buts de l'enquête a consisté à étudier les dynamiques du conflit sur le procès de pollution et d'accès à l'eau potable de la région atlantique et du nord du Costa Rica dans des espaces territoriaux déterminés où l'interaction entre la ressource hydrique, la production de l'ananas et les communautés est notable.

Mots-clés: Rapport de force, sujet collectif, mouvements sociaux écologistes, ressource hydrique. 


\section{Introducción}

En este artículo se propone una reflexión sobre poder y conflicto social por el agua con perspectiva de clase, mediado metodológicamente por inversiones de capital dedicadas a la producción de piña para exportación. La tesis central del trabajo es que dicho capital representa a fracciones de clase dominante en el sector agrícola, en su momento, políticamente apoyadas por el Estado en detrimento de otras clases y fracciones más débiles, lo que demuestra «el carácter de clase» que contiene el Estado costarricense.

La estructura del documento inicia con una reseña metodológica; luego, el primer apartado revisa, aunque no de forma exhaustiva, algunos trazos del contexto social, económico y político de las décadas previas a los conflictos por el agua, esto para comprender las relaciones de poder que se observan hoy entre los actores en conflicto. El segundo contiene las categorías de investigación relacionadas con poder, conflicto y relaciones de fuerza surgidas en la dinámica socio-política en torno del agua. El tercero, hace una aproximación empírica a partir de la categoría de poder antes discutida. Por último, se resumen las principales conclusiones.

\section{Metodología}

La investigación tiene un enfoque cualitativo, está basada en entrevistas aplicadas a cuatro tipos de sujeto descritos a continuación:

\section{Cuadro 1 Tipos de sujeto indagados}

1. Grupo de líderes de las Asociaciones Administradoras de Sistemas de Acueductos y Alcantarillados Comunales (ASADAS) en los siguientes lugares: cantón de Guácimo, provincia de Limón; cantón Los Chiles y el distrito de Pavón, comunidades El Tanque y Veracruz de Pital, del cantón San Carlos (zona norte) y Dulce Nombre de Naranjo, cantón de Naranjo, provincia de Alajuela.

2. Funcionarios del MINAE, específicamente en la Dirección de Aguas y el Sistema Nacional de Áreas de Conservación (SINAC) de las respectivas regiones atlántico y norte.

3. Dos funcionarios de municipalidades, uno en la zona norte y otro en la zona atlántica; este último con vínculos de trabajo en organizaciones ambientales de Guácimo.

4. Dos lideresas comunales, una de ellas también es integrante del Frente Nacional de Sectores Afectados por la Producción Piñera (FRENASAPP).

Fuente: Elaboración propia.

El criterio metodológico de selección de entrevistados siguió la estrategia del «muestreo teórico» ${ }^{1}$, cuyo «número de casos estudiados carece relativamente de

${ }^{1}$ Stephen John Taylor y Bogdan, Robert, Introducción a los métodos cualitativos de investigación (Buenos Aires: PAIDOS, 1987).

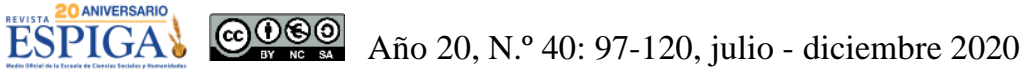


importancia. Lo esencial es el potencial de cada "caso" para ayudar al investigador en el desarrollo de comprensiones teóricas sobre el área estudiada de la vida social» ${ }^{2}$; o sea, comprender a «profundidad» el fenómeno estudiado. Para su escogencia se utilizó la técnica de la «bola de nieve» ${ }^{3}$ en este caso, se hizo por medio de contactos previos con un informante, quien sugirió a las demás personas.

Para complementar, se recurrió a fuentes de primera mano (periódico impreso y digital), tesis y artículos de investigaciones de la Universidad de Costa Rica (UCR) en los cuales se problematiza el agua; así como leyes de la República, documentos oficiales y de organizaciones sociales para precisar el objeto de estudio. También se recurrió a fuentes secundarias especializadas, tanto de sitios web como artículos y libros que contienen debates de nivel teórico-metodológico. Como todo producto académico, se pretende dar un aporte de conocimiento, desde la sociología, a la tematización del recurso hídrico relacionado al poder, con enfoque de clase y una mirada marxista heterodoxa, lo cual no limita considerar autores que trabajan con otros referentes teóricos cuando aporten al debate en ciencias sociales.

\section{Contexto del conflicto por el recurso hídrico}

Para entender el conflicto social por el agua, se introducen algunos elementos contextuales, esto con el fin de localizar algunos elementos básicos que expliquen por qué este recurso siempre se ha considerado como algo consustancial y accesible al entorno cotidiano, sobre todo si se proyecta décadas atrás; aunque, últimamente emerge, ya no como un recurso natural más, sino como uno muy particular y codiciado.

Esto se da por las cualidades intrínsecas del agua para realizar la vida individual y social en medio de intereses diversos entre actores creados a partir de ciertas valoraciones pragmáticas, en el sentido de que el agua es fundamental, ya no solo porque el cuerpo requiere de agua para vivir; sino, además, para desarrollar actividades que implican alguna lógica productiva y económica; o bien, como recurso esencial sin el cual no es posible obtener estándares de desarrollo humano en las sociedades contemporáneas.

Desde una visión filosófica, el agua puede apreciarse también como principio vital dador de vida; o sea, sin agua no es posible concebir la vida en la Tierra. Tal visión, no está exenta de complejidad, contiene una abstracción que se debe situar y develar a partir de una reflexión crítica. Aunque parezca risible plantearlo, al partir de la racionalidad weberiana «medio-fin», las valoraciones pragmático-utilitarias predominan en las sociedades capitalistas, quedando opacada y reducida la visión filosófica y profunda sobre el agua como principio ordenador de la vida en el planeta. Siguiendo este pragmatismo, el agua es un recurso potencial o «materia prima» para crear riqueza y acumulación de ganancia; claro está que, en este caso, se trata de asumir el agua desde una mirada instrumental y economicista para asegurar la «vida» del capital y su reproducción. De forma sucinta, esta es la lógica con la cual se asimila el agua en el capitalismo. Se nota aquí una «inversión» del principio vital

${ }^{2}$ Stephen John Taylor y Bogdan, Robert, Introducción a los..., 108.

${ }^{3}$ Stephen John Taylor y Bogdan, Robert, Introducción a los..., 109. 
enunciado anteriormente, donde la noción de vida que provee el agua en el planeta es transmutada en, y, por la vida del capital» y por ella.

Hinkelammert ${ }^{4}$ en una antología preparada por la filósofa argentina Estela Fernández Nadal, titulada La vida o el capital: el grito del sujeto vivo y corporal frente a la ley del mercado, se basa en una cita de Marx $^{5}$ en la que plantea que: «[P]ara que viva el capital, tiene que vivir el obrero. El capital extrae su vida del obrero, y, por tanto, tiene que mantener en vida al obrero para poder vivir él... [pero el capital] asegura la vida solamente a los obreros necesarios para su propio proceso de vida $(\ldots){ }^{6}{ }^{6}$.

Al mediar la cita en la lógica de inversiones de capital en empresas piñeras, los altos volúmenes de agua utilizados como materia prima en la producción (aparte de que necesita que el obrero agrícola «viva», aun siendo una fuerza de trabajo explotada), también requiere que viva la naturaleza, el agua, que este recurso siempre esté disponible, eso sí, solo en el tanto y cuánto lo requieran estas empresas para producir la fruta. Al completar el análisis se tiene que: el capital invertido en la piña extrae «su vida», por una parte la del obrero agrícola a quien le es arrancada una cuota de plusvalor («trabajo impago»), la cual, al sumar la de todos los obreros de las plantaciones, y una vez que la piña se convierte en mercancía, el capitalista obtiene una cuota de plusvalía.

Dicho capital también extrae su vida de la naturaleza y del agua en particular, al ser utilizada en el proceso de irrigación en campos piñeros, incluso hasta la etapa final del lavado de la fruta; por lo que, resumiendo la reflexión, surge el siguiente axioma: El capital invertido en empresas piñeras vive, si vive el obrero agrícola y si vive la naturaleza y con ella la porción de agua requerida en el proceso productivo. Estos son los límites del capital en los campos piñeros de Costa Rica; sobrepasarlos, parafraseando a Hinkelammert, es «suicidio».

Como la naturaleza no es producida por el ser humano, el capital, en este caso, se ahorra además el costo de producir esta peculiar materia prima utilizada en sus procesos (salvo el costo de abrir pozos o desviar cauces de ríos). Como es un capital de inversionistas que no han sido educados para reponer o mitigar el daño que sus inversiones producen en la naturaleza, no existe un compromiso ético de responsabilidad para preservar ni tampoco de innovar en los procesos productivos para reponer lo que el capital destruye. Así, se está ante una «destrucción intensiva», lejos de lo que sería un proceso de «destrucción creativa», analizada por Josep Schumpeter en el capitalismo de la primera mitad del siglo XX, relacionado con el principio de «innovación» del empresario como herramienta transformadora y como fuerza que está detrás del crecimiento económico a largo plazo; un «proceso que se considera el hecho esencial del capitalismo» ${ }^{7}$.

La crítica a este capital, siguiendo a Schumpeter, está en que no ha sido capaz de crear un proceso de «innovación» tecnológica para superar malas prácticas

\footnotetext{
${ }^{4}$ Franz Josef Hinkelammert, El grito del sujeto vivo y corporal frente a la ley del mercado (Buenos Aires: CLACSO/ALAS, 2017).

${ }^{5}$ Franz Josef Hinkelammert, El grito del...

${ }^{6}$ Franz Josef Hinkelammert, El grito del..., 79.

${ }^{7}$ Jacobo de la Corte Carmona, Schumpeter y la destrucción creativa de instituciones por los innovadores (Madrid: Universidad Pontificia Comillas, 2015), 8. 
productivas que contaminan y destruyen el ambiente, con lo que de paso se aleja de principios claves de la economía capitalista formal, tal como es innovar procesos en forma permanente y reproducir el sistema en el tiempo. Nótese que este capital lo que destruye es naturaleza, hecho que podría reducirse al invertir en investigación, desarrollo e innovación tecnológica, independientemente de que se reproduzca de forma ampliada ${ }^{8}$, lo cual no está en duda.

En todo caso, la premisa de la innovación como el hecho esencial del capitalismo, ha sido cuestionada desde hace tiempo por el pensamiento crítico. Rosa Luxemburgo ${ }^{9}$ planteaba que «El capitalismo necesita, para su existencia y desarrollo, estar rodeado de formas de producción no capitalistas» ${ }^{10}$. En el caso en estudio, el capital penetró un territorio rural donde prevalecían formas de economía tradicional, sobre todo en su área fronteriza, considerada de «bajo desarrollo». El capital se instala, modifica el espacio y el paisaje rural, pero también la vida comunitaria de las personas al imponer unas relaciones sociales a «su imagen y semejanza», subsumiendo su dinámica y formas tradicionales en la producción de «valores de uso» para la vida. Por eso, este capital invertido en la zona significa que:

(...) su ubicación no es casual en espacios en donde todavía operan formas de reproducción de la vida cotidiana que no necesariamente están mediadas por relaciones capitalistas, como por ejemplo el trabajo doméstico que hacen las mujeres, la producción de alimentos de subsistencia familiar y la gestión comunitaria de los bienes comunes. Son estas prácticas las que permiten finalmente la reproducción de la fuerza laboral y de las cuales las empresas hacen uso para pagar tasas salariales inferiores que por sí solas no sostienen dicha reproducción ${ }^{11}$.

Entonces, estas formas de trabajo constituyen prácticas anticapitalistas, «atípicas según la visión ortodoxa del capitalismo» ${ }^{12}$, que tienen lugar en las «orillas» del sistema al estar en oposición, al menos, a dichos postulados básicos, entre otros no considerados. Lo que, parafraseando al sociólogo alemán Gunder Frank ${ }^{13}$, conduce

\footnotetext{
8 Al respecto, una publicación en el Semanario Universidad, sobre una investigación realizada sobre el tema comenta: Entre 1991 y 2014, la piña aumentó su productividad en un 91\%, pasando de producir 29 toneladas de fruta por hectárea a 56 toneladas (Rodríguez, 2015). Este aumento no necesariamente tiene que ver con una mejora tecnológica...aunque sí puede estar relacionado con el mejoramiento de insumos...fertilizantes, herbicidas...tiene también que ver con un alza en la intensidad del trabajo manual -que continúa siendo prioritario - un aumento de horas en las jornadas laborales -aunque no en el promedio de trabajadores (Marylaura Acuña y Mauricio Álvarez, Situación laboral y ambiental de las piñeras en la zona norte, Programa Kioscos Ambientales, UCR, 5 de febrero del 2019).

${ }^{9}$ Rosa Luxemburgo, La acumulación de capital (S. d.: Ediciones Sedov Germinal, 1913).

${ }^{10}$ Rosa Luxemburgo, La acumulación... 179.

${ }^{11}$ Marylaura Acuña Alvarado y Álvarez Mauricio, s. f. «Situación laboral y ambiental de la piñeras [sic.] en la Zona Norte», Kioscos ambientales, acceso: 19 de octubre, 2020, https://kioscosambientales.ucr.ac.cr/opinion/46-opinion/1673-situaci\%C3\%B3n-laboral-yambiental-de-la-pi\%C3\%B1eras-en-la-zona-norte.html

${ }^{12}$ Armando Bartra, El hombre de hierro. Los límites sociales y naturales del capital. Ciudad de México: UNAM, 2008, 121.

${ }^{13}$ André Gunder Frank, Lumpenburguesía: lumpendesarrollo. Dependencia, clase y política en Latinoamérica (Barcelona: Ediciones de bolsillo, 1972).

ESPIGA' @(1)(?) Año 20, N. . 40: 97-120, julio - diciembre 2020 
a identificar a estas fracciones de clase como «lumpenburguesía ${ }^{14}$ que parasitan, en este caso, mediante la expoliación de recursos naturales y explotación de la fuerza de trabajo, incluida la subsunción de formas de vida comunitarias.

En esta ecuación productivista, el obrero agrícola «pertenece» al capital, pero en una relación de lucha capital-trabajo; mientras que la naturaleza, o la porción de ella, que es apropiada y explotada, también pasa a sus dominios. Por su parte, la maquinaria agrícola, las tecnologías incorporadas al proceso de producción (abonos, agroquímicos, herbicidas, fungicidas, foliares, etc.) y el equipo tecnológico necesario en la administración de la empresa, vendrían a ser, de forma conjunta, «la maquina» que Marx analizara en la producción, tanto agrícola como fabril. Dicha máquina, siendo también un «instrumento de trabajo», se transforma en algo diferente; es decir, «en un mecanismo de producción cuyos órganos son hombres... [Se trata de un autómata que es movido por] un primer motor que no recibe la fuerza de otra fuente motriz» ${ }^{15}$.

La fuerza motriz del obrero mueve la máquina y esta última tiene su principio de vida en la vida misma de aquel: «En su trabajo productivo racional, el hilar, el tejer, el forjar, el que con su simple contacto hace resucitar los medios de producción entre los muertos, les infunde vida como factores del proceso de trabajo y los combina, hasta formar con ellos productos (...)». Se trata de la inversión de aquella imagen según la cual Dios, como primer motor impulsado, da vida al humano por su simple contacto con un dedo. Aquí la maquinaria, con su «primer motor», recibe la vida por el contacto con el hombre-obrero ${ }^{16}$.

En las piñeras, la máquina movida por el obrero agrícola se utiliza sobre todo en procesos y lapsos desde la preparación de (la tierra, la siembra y hasta que sale el producto; pero la otra parte sustantiva de su fuerza de trabajo, se invierte como «fuerza motriz» en la mayor parte del proceso productivo, que deriva en una especie de «maquina corporal» y humana, utilizada en extenuantes jornadas de trabajo de las que el capital extrae, de forma directa, su energía, su vida y su sangre. Aquí no hay mediaciones en el proceso de trabajo, el capital absorbe directamente la vitalidad muscular del obrero agrícola para su reproducción.

\section{Peculiaridad del neoliberalismo}

Otro elemento que explica el conflicto hídrico entre inversores y comunidades rurales, desde finales de la década de 1990, tiene su origen en el patrón de desarrollo socio-económico adoptado por Costa Rica durante al menos las tres últimas décadas. Este patrón se identifica con las tesis centrales del neoliberalismo, ya desde la década de 1980.

Vargas Solís ${ }^{17}$ brinda un concepto particular y esclarecedor del neoliberalismo en Costa Rica, que denomina Proyecto Histórico Neoliberal (PHN), el cual es adecuado

\footnotetext{
${ }^{14}$ André Gunder Frank, Lumpenburguesía...

${ }^{15}$ Franz Josef Hinkelammert, El grito del..., 271-311.

${ }^{16}$ Franz Josef Hinkelammert, El grito del..., 151-153.

${ }^{17}$ Luis Paulino Vargas Solís, «El proyecto histórico neoliberal en Costa Rica (1948-2015): devenir histórico y crisis». Revista Rupturas 6, n. ${ }^{\circ} 1$ (2016).
} 
para entender el trasfondo que explicaría el origen del conflicto por el agua en el país, al plantear:

El concepto de «proyecto histórico» es entonces político porque implica un determinado arreglo de las relaciones de poder internas y externas; es económico en cuanto identifica las fuerzas económicas dominantes, la organización de los mercados y los sectores punta de acumulación de capital; ideológico porque responde a una visión de mundo generalmente coherente con aquellas relaciones de poder y esta estructura productiva y de acumulación; cultural porque asimismo da lugar a formas de vida que se articulan de forma más o menos coherente o contradictoria, respecto de las bases de acumulación y la organización y división del trabajo, así como de las relaciones político-ideológicas hegemónicas...el concepto específico de «Proyecto Histórico Neoliberal» [lo utiliza] para caracterizar sintéticamente los elementos estructurales como el devenir y evolución dinámica de tales estructuras durante el período 1984-2015 en Costa Rica ${ }^{18}$.

En línea con lo planteado por el PHN, se analizan las inversiones en piña para exportación en la zona atlántica y norte, las cuales combinan capital nacional y transnacional. Dicho proyecto neoliberal, concebido como parte del nuevo patrón de acumulación capitalista de aquellos años mediante los Planes de Ajuste Estructural (PAE), fue impulsado desde el Estado y con dinero público, fenómeno de mediados de la década de 1980 en adelante, del que se brindan algunos elementos.

Para llevar a cabo la reestructuración económica que exigían los PAE, la clase dominante impulsó, desde el Legislativo, el fomento de las exportaciones ${ }^{19}$; con esta medida «se redujo la inversión estatal y se apoyó el crecimiento de la inversión privada»; para hacerla efectiva en el campo productivo «las ayudas y estímulos estatales se trasladaron de los productores nacionales que abastecían al mercado interno hacia los exportadores de los productos llamados no tradicionales como flores, frutas y raíces, capaces de insertarse exitosamente en los mercados internacionales y crear riqueza» ${ }^{20}$; es decir, «Se fortaleció el aparato exportador de productos agrícolas no tradicionales a terceros mercados, canalizando transferencias (Certificados de Abono Tributario, CAT) (...) y creando regímenes de admisión temporal y de zonas francas» ${ }^{21}$.

Otras medidas sustanciales para hacer realidad dichos incentivos y crear la clase de los exportadores son las contenidas en la Ley de Emergencia para el Equilibrio

\footnotetext{
${ }^{18}$ Luis Paulino Vargas Solís, «El proyecto..., 149-150.

${ }^{19}$ Se refiere a los Incentivos para las exportaciones. Los beneficios que en adelante se establecen se podrán conceder por un período máximo de doce años, a partir del período fiscal del impuesto sobre la renta $\mathrm{N}^{\circ} 84$, a las exportaciones no tradicionales a terceros mercados. Se entenderá por «exportaciones no tradicionales» $\mathrm{y}$ «terceros mercados» los que determine el reglamento que al efecto emita el Poder Ejecutivo por medio del Ministerio de Comercio Exterior... Artículo 65. Ley del Impuesto sobre la Renta, No. 7092.

${ }^{20}$ Blanco, 2015, 9.

${ }^{21}$ César Zúñiga Ramírez, «Reforma del Estado en Costa Rica y transformaciones institucionales durante la administración Arias Sánchez (1986-1990)», Revista de Ciencias Sociales 81 (1998), 22. 
Financiero del Sector Público, No. 6955 22 , aprobada en febrero de 1984, en un contexto de crisis; además, de estar en un marco de exigencias establecidas por el Fondo Monetario Internacional (FMI), que buscaba reorientar la economía ${ }^{23}$.

Algunas medidas creadas por esta ley son: el contrato de exportación, la reducción de tarifas portuarias especiales, simplificar los procedimientos de exportación, crédito financiero con tasas de interés preferenciales para los empresarios, reducciones impositivas, Certificados de Abono Tributario (CAT), Certificados de Incremento de las Exportaciones (CIEX), exención de impuestos de importación para materias primas y envases no fabricados en el país y la reducción del $100 \%$ del impuesto sobre la parte de las utilidades netas del período de productos no tradicionales, entre otras ${ }^{24}$.

Sin estas medidas, más el apoyo con recursos estatales para hacer efectivos los incentivos fiscales, era difícil, por no decir imposible, crear un sector de exportadores muy dinámico y con participación del capital extranjero, que fue desplazando al «viejo» sector exportador y se pasó del proteccionismo del modelo sustitutivo de importaciones, tan criticado por los neoliberales, a un «neoproteccionismo» ${ }^{25}$.

Como consecuencia, sobrevino una capacidad expansiva de la actividad piñera, particularmente en la zona norte:

De esta forma también cambió el peso relativo de la producción por zona, es así que, en el año 1980, un 90 \% de la producción se ubicaba en la Región Brunca, mientras que, en el año 2004, el 52 \% se ubicó en la Región Huetar Norte $^{26}$. Para el año 2014, esta región sigue concentrando el mayor porcentaje de producción, ya que podemos determinar que aproximadamente $61 \%$ de la producción de piña del país sale de esta zona ${ }^{27}$.

Pero, este dinamismo del sector trae también la dialéctica del conflicto que ha sido intensa, sobre todo en ciertos territorios y más allá de la relación capital-trabajo, al involucrar las relaciones íntimas de las comunidades afectadas. En adelante, con la mediación de este tipo de inversiones, se harán algunas reflexiones teóricas para comprender mejor las indagaciones empíricas del estudio.

${ }^{22}$ Ley $\mathrm{N}^{\circ}$ 6955, de 24 de febrero de 1984, Ley para el Equilibrio Financiero del Sector Público (La Gaceta $\mathrm{N}^{\circ} 45$ del 2 de marzo de 1984).

${ }^{23}$ Jorge Rovira Mas, Costa Rica en los años 80 (San José, Editorial Porvenir, 1988).

${ }^{24}$ Jorge Rovira Mas, Costa Rica ..., 84-85.

${ }^{25}$ Luis Paulino Vargas Solís, «El proyecto...

${ }^{26}$ Aravena, 2005.

${ }^{27}$ Karina Valverde Salas, Porras Montero, Mariana y Jiménez Corrales Andrés, «La expansión por omisión: Territorios piñeros en los cantones Los Chiles, Upala y Guatuso, Costa Rica (2004-2015)» (Vigésimosegundo Informe Estado de la Nación en Desarrollo Humano Sostenible, 2018), 8. 


\section{Poder, relaciones de poder y recurso hídrico}

El poder, como «relaciones de fuerza», es la perspectiva de un «marxismo heterodoxo» ${ }^{28}$ que Poulantzas asume en su última etapa de vida intelectual, donde la «columna vertebral de la lucha de clases [es determinante] como factor que permite descifrar las estructuras del poder estatal...» ${ }^{29}$.

$\mathrm{Al}$ respecto, Poulantzas ${ }^{30}$ plantea:

(...) el poder no es, en sí mismo una cantidad o cosa que se posea, ni una cualidad ligada a una esencia de clase, a una clase-sujeto (la clase dominante) (...) Se debe entender por poder, aplicado a las clases sociales, la capacidad de una o varias clases para realizar sus intereses específicos. El poder referido a las clases sociales es un concepto que designa el campo de lucha, de las relaciones de fuerza y de las relaciones de una clase con otra: los intereses de clase designan el horizonte de la acción de cada clase con relación a las otras ${ }^{31}$ (El destacado es del autor).

En tal noción de poder, el núcleo contradictorio entre las clases es la «relación» misma a la que esta contradicción alude: los «intereses» de clase. Una relación de lucha donde la clase más fuerte políticamente infringe ataques a su par más débil y, cuando la primera cree estar en la cima del poder, es a su vez desestabilizada del privilegiado lugar que creía tener hasta quedar también en una posición de subalternidad al ser sustituida por otra clase con más poder. Es una lucha cruenta, de infidelidades y traiciones, de «coces» dirá Marx en El 18 brumario de Luis Bonaparte. Esta no es una escena solamente de la Francia de mediados del siglo XIX, se puede ver también en el recorrido que hace Vargas ${ }^{32}$ sobre el PHN costarricense en las sucesivas «fases» neoliberales, donde una clase, por la que antes se había apostado, es desplazada para ascender al poder a la que viene empujando detrás.

${ }^{28}$ Gilberto Tobón Sanín, «La obra de Nicos Paulantzas y la teoría marxista del derecho y la política», Revista Jurídica Mario Alario D’Filippo 3, n. ${ }^{\circ} 1$ (2011): 36-58.

Para comprender el marxismo de Poulantzas hay que considerar las tres etapas de su pensamiento; la primera, es de influencia «fenomenológica Husserliana» y la «teoría existencialista-marxista de Sartre» (Crítica de la razón dialéctica) pero en búsqueda del análisis marxista del fenómeno «jurídico-político» del capitalismo. La segunda, es la etapa del «marxismo-estructuralista» con influencia de Althusser, donde el concepto de «estructura» es la clave de esta «escuela metodológica» de los años 70, la obra que mejor expresa esta postura es Clases sociales y poder político en el Estado capitalista. La tercera, está signada por el agotamiento del llamado «marxismo ortodoxo» y la crisis del «socialismo real», ante lo cual Poulantzas rompe con el «marxismo ortodoxo» y dogmático e impulsó la teoría de un «marxismo heterodoxo» donde el Estado es entendido como «una condensación de una relación de fuerzas» atravesado por la lucha de clases, pero incluye a un amplio movimiento social: feminismo, ecologismo, etc.». La obra que resume esta nueva postura teórica es Estado, poder y socialismo.

${ }^{29}$ Gilberto Tobón Sanín, «La obra de Nicos..., 57.

${ }^{30}$ Nicos Poulantzas, Estado, poder y socialismo (Ciudad de México: Siglo XXI Editores, 1987).

${ }^{31}$ Nicos Poulantzas, Estado..., 177.

${ }^{32}$ Luis Paulino Vargas Solís, «El proyecto... 
Así, el recurso hídrico está en medio de una trama específica de intereses y relaciones de poder que trasciende la vida social de las comunidades rurales, tal y como se verá. Incluso, se encuentra más allá de los límites del Estado-nación, al insertarse en los cálculos de utilidad y los negocios globales del capitalismo realmente existente. Con la globalización, es notoria la presencia de transnacionales del agua por todos los continentes, producto de los «ajustes» estructurales y el «libre mercado», promovido por el Banco Mundial y el FMI.

En Costa Rica, si bien el agua es administrada por el Estado, ha sido sometida a un intenso proceso de explotación y liberalización «solapada», a veces difícil de desentrañar, dada su amplia institucionalidad involucrada, competencias cruzadas, descoordinación y contradicciones de poder ligado a intereses económicos; aunque formalmente su manejo se haga de acuerdo con la Ley de Aguas de 1942. Esto adquirió matices especiales luego de aprobado el Tratado de Libre Comercio entre Centro América, República Dominicana y EE.UU., debido a la amplitud de temas y normativa específica en materia de negocios, donde el agua es un recurso estratégico para EE.UU. como parte de la agenda de negocios en el capitalismo globalizado.

Así, se está ante una liberalización de hecho, no de derecho, con gran cantidad de empresas que incursionaron en la «industria» del agua embotellada; luego, de las concesiones a empresas nacionales y extranjeras como las piñeras, entre otras, que si bien son reguladas -en principio- por normativa del Ministerio de Ambiente y Energía (MINAE), la vigilancia se ha vuelto un asunto complejo y conflictivo.

$\mathrm{Al}$ retomar la noción de poder en Poulantzas ${ }^{33}$ dada líneas arriba, es sugerente al plantear que el poder «no es una cantidad ni una cosa que se posea»o un atributo propio de la clase dominante, sino la «capacidad de una o varias clases para realizar sus intereses». Con los elementos ya analizados, se puede plantear la tesis de que las clases exportadoras de productos «no tradicionales» han sido capaces de «realizar sus intereses específicos» con el apoyo del Estado.

Goran Therborn ${ }^{34}$ clarifica, aún más la tesis de Poulantzas, al partir de dos elementos teóricos. El primero, es que para captar la dominación «lo fundamental ha de girar en torno al carácter de clase del poder del Estado, ya que la clase dominante queda definida como tal por el ejercicio de ese poder ${ }^{35}$. Se ha dicho que, en la década de 1980, hubo una clase exportadora que fue «potenciada» desde el Estado con todas las ventajas y justificaciones, como la que formuló Eduardo Lizano en 1984, en referencia a que los exportadores «hiciesen clavos de oro» ${ }^{36}$; pero al mismo tiempo, se atacaba a otras clases orientadas al mercado nacional, a las cuales, desde el mismo Estado, se les puso «freno» a su desarrollo como clase, lo que, siguiendo a Therborn, es un fenómeno que se da a partir de un conflicto entre la burguesía por «causas económicas y políticas» ${ }^{37}$.

\footnotetext{
${ }^{33}$ Nicos Poulantzas, Estado...

${ }^{34}$ Goran Therborn, ¿Cómo domina la clase dominante? Aparatos de Estado y poder estatal en el feudalismo, el capitalismo y el socialismo (Ciudad de México: Editorial Siglo XXI, 1987).

${ }^{35}$ Goran Therborn, ¿Cómo domina ..., 171.

${ }^{36}$ Luis Paulino Vargas Solís, «El proyecto...

${ }^{37}$ Goran Therborn, ¿Cómo domina ..., 190. 
Efectivamente, en el escenario internacional había una crisis económica que urgía el replanteamiento de estrategias para salir de ella, esto propiciaba, a lo interno, un debate político e ideológico intenso con ingredientes geopolíticos en el marco de la Guerra Fría; en la Asamblea Legislativa se expresó con dos posiciones contrapuestas: la primera, los representantes de la clase dominante en el Congreso y otras instituciones de gobierno, que ya tenían la mira puesta en las exportaciones de «productos no tradicionales» orientada a una «desregulación del mercado interno» y «reducción del gasto público», entre otras medidas estructurales. La segunda, a los representantes de la clase tradicional ligada con la agricultura (tradicional), que no logra adaptarse a las exportaciones y cuyas actividades económicas se orientaban al mercado interno; incluso, habría que agregar a una fracción de la industria que no logra hacer la «reconversión industrial» para exportar a terceros mercados y que, al bajar el arancel de importación, quedó desprotegida «frente a la competencia externa ${ }^{38}$. Ambas fracciones de clase se inclinan por un proceso más «parsimonioso, gradual y a largo plazo» que permitiera fortalecer el mercado interno y regional centroamericano ${ }^{39}$, lo que posibilitaría a esta clase rezagada una adaptación paulatina a las nuevas condiciones del mercado.

Estos elementos socio-políticos sentaron las bases de una «relación conflictiva» entre estas clases, con repercusiones hasta el presente, donde el apoyo del Estado a favor de la clase exportadora fue determinante «a partir de una política de fomento deliberado por parte del Estado» ${ }^{40}$ para posicionarla en «terceros mercados», lo cual confirma la tesis de Poulantzas ${ }^{41}$ en el sentido de que el poder de una clase no es una «sustancia que tenga en sus manos», el poder es una «relación de fuerzas» en lucha $\mathrm{y}$, por tanto, construido en medio de una tensión. Para Therborn ${ }^{42}$, la intervención sistemática del Estado a favor de una clase, la posiciona en el «ejercicio exclusivo del poder», esta acción revela el «carácter de clase» que contiene un Estado, en este caso, el carácter de clase del Estado costarricense.

El segundo elemento propuesto por Therborn ${ }^{43}$ señala que «el poder político y el poder del Estado deben analizarse en relación con los procesos de reproducción y transformación social» ${ }^{44}$ ¿Qué es lo que mantiene o reproduce el Estado? Es su pregunta; en breve, son «las relaciones de producción y las fuerzas productivas, el carácter del aparato de Estado y la particular superestructura ideológica (...) $\rangle^{45}$. Reproducir determinadas relaciones de producción es mantener las formas de explotación del trabajo dentro de un «determinado modo de producción», así como promover «la acumulación de capital». En los territorios piñeros existen las condiciones de explotación para la acumulación de capital; además, hay violaciones a derechos laborales de las personas trabajadoras, como se evidencia en un estudio de investigadores de Kioskos ambientales:

\footnotetext{
${ }^{38}$ Francisco Esquivel, «Costa Rica, de la crisis económica al ajuste estructural conservador», en Crisis Económica y ajuste estructural (San José: EUNED, 2007), 143.

${ }^{39}$ César Zúñiga Ramírez, «Reforma...

${ }^{40}$ Luis Paulino Vargas Solís, «El proyecto...

${ }^{41}$ Nicos Poulantzas, Estado...

${ }^{42}$ Goran Therborn, ¿Cómo domina...

${ }^{43}$ Goran Therborn, ¿Cómo domina...

${ }^{44}$ Goran Therborn, ¿Cómo domina ..., 171.

${ }^{45}$ Goran Therborn, ¿Cómo domina..., 172. 
Un informe suministrado al Consejo Universitario de la UCR sobre infracciones detectadas en visitas del Ministerio de Trabajo a fincas piñeras, señala que existen mayores porcentajes de infraccionalidad en cuanto a la protección personal (uso de vestimentas e insumos adecuados), acceso a servicios sanitarios según lo estipulado legalmente, pago de horas extras, hostigamiento sexual, salario mínimo, entre otros ${ }^{46}$.

El informe agrega otras violaciones de derechos tales como: condiciones de explotación laboral; jornadas excesivas más allá de las permitidas por el Código de Trabajo; y persecución sindical a personas afiliadas, algunas veces despedidas; situación que ha llevado a los trabajadores organizados en el sindicato (SITRASEP) a realizar una huelga durante el $2018^{47}$. Al iniciar enero de 2019, estallaron dos huelgas más en la zona de Los Chiles y Upala, sitios que, entre muchos conflictos, reclamaba a las empresas sus derechos laborales ${ }^{48}$. Este dato es trascendente porque no es un fenómeno aislado en la zona norte, las personas obreras organizadas en este sindicato, tienen varios años de mostrar un nivel sostenido de organización sindical mediante una lucha que reposiciona, en época de «neoliberalismo tardío», la praxis dialéctica entre el capital y el trabajo.

En cuanto a los salarios pagados por debajo del mínimo, el Ministerio de Trabajo y Seguridad Social no maneja datos actualizados; el último localizado es de 2010. Tampoco tiene una desagregación por actividades para obtener un dato específico de las piñeras. Se recurrió entonces al dato cualitativo de fuentes primarias. Una especialista de la organización no gubernamental internacional OXFAM (por sus siglas en inglés), en gira de campo por las piñeras de la zona norte, concluye que ${ }^{49}$ «hay problemas en la cadena de suministros en Costa Rica, por ejemplo, no hay salario digno, en algunos casos no se cumple con el salario mínimo».

Por su parte, una tesis de la UCR, titulada «Más allá del trabajo asalariado: Implicaciones sociales en el uso del tiempo no remunerado de trabajadoras y trabajadores vinculados al monocultivo de piña en la comunidad de Pital de San Carlos en los años 2012-2013», señala que:

(...) los salarios son altamente insuficientes: en muchos casos están por debajo del mínimo legal. Cada vez que el Consejo Nacional de Salarios hace ajustes, las piñeras se hacen de la vista gorda, sumergiendo más en la pobreza a las y los trabajadores» (Leitón, 2008:19), citado por Avendaño, Ramírez y Segura (2014, p.148. 149). Además, existe «El trabajo a destajo [que] es llevado a cabo principalmente en las empacadoras, donde se les

\footnotetext{
${ }^{46}$ Marylaura Acuña Alvarado y Álvarez, Mauricio, s. f. «Situación laboral...

${ }^{47}$ Marylaura Acuña Alvarado y Alvarez Mauricio, s.f., «Situación laboral..., 1.

${ }^{48}$ Socialismo Hoy, «Piñeras: Tres huelgas en menos de una semana en Zona Norte», 18 de enero de 2019, http://socialismohoy.com/pineras-3-huelgas-menos-semana-zona-norte/

${ }^{49}$ Vinicio Chacón , «Trabajadores de la piña viven clima de explotación laboral», Semanario Universidad, 23 de marzo de 2016, acceso: 19 de octubre, 2020, https://semanariouniversidad.com/pais/trabajadores-la-pina-viven-clima-explotacionlaboral/

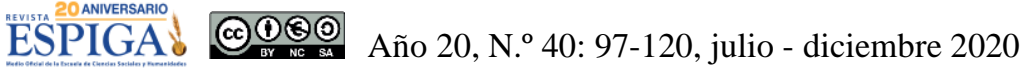


paga por las cajas empacadas y no por hora. De ahí que los salarios en esta área de la agroindustria sea uno de los más fluctuantes» ${ }^{50}$.

En contraste, las acciones del Estado tienden a favorecer la acumulación de capital para el sector exportador más dinámico de la piña; la fracción dominante de la burguesía, tanto nacional como extranjera, que en la globalización aparece reconfigurada en una «alianza» de clase, en la cual, la fracción del capital transnacional tendría la hegemonía para decidir el tamaño de las inversiones, la intensidad del trabajo y la cuota de plusvalor arrancada al trabajador, pero en medio de la resistencia obrera que también tiene su propia agenda de lucha.

\section{Necesidad del poder político}

Adolfo Sánchez Vásquez, estudioso del pensamiento de Marx, cree que el clásico no podía ignorar la importancia de una «teoría del poder» y propuso conceptos relacionados con esta categoría, entre ellos la «necesidad del poder político», entendido como una instancia necesaria de una sociedad divida por antagonismos irreconciliables. En ella, este poder político representa el lugar de la «conciliación» entre las clases; siendo este carácter de clase la originalidad de Marx. Es un concepto que refiere al poder político o poder del Estado. Engels lo expresa así:

(...) es un producto de la sociedad cuando llega a un grado de desarrollo determinado; es la confesión de que esa sociedad se ha enredado en una irremediable contradicción consigo misma y está dividida por antagonismos irreconciliables, que es impotente para conjurar. Pero a fin de que estos antagonismos, estas clases con intereses económicos en pugna, no se devoren a sí mismas y no consuman a la sociedad en una lucha estéril, se hace necesario un poder situado aparentemente por encima de la sociedad y llamado a amortiguar el choque, a mantenerlo en los límites del «orden» $(\ldots)^{51}$.

Según Sánchez ${ }^{52}$, la idea sobre una sociedad divida por antagonismos irreconciliables no es original de Marx, recorre obras del pensamiento desde Maquiavelo, pasando por Hobbes hasta Hegel, que para él confluyen en frases como «el hombre es el lobo del hombre» (Hobbes), o la tesis de «la guerra de todos contra todos» (de Adam Smith y Hegel), las cuales expresan ese antagonismo entre los humanos; pero la originalidad de Marx está en observar en ello «el carácter de clase de las fuerzas en pugna» y que el equilibrio y la solución de las contradicciones solo tienen, en apariencia, «un carácter universal», o sea, por encima de intereses

\footnotetext{
${ }^{50}$ Karla Rebeca Avendaño Hernández, Ramírez Mora, Karla Patricia y Segura Hernández Ana Gabriela, «Más allá del trabajo asalariado: Implicaciones sociales en el uso del tiempo no remunerado de trabajadores y trabajadores vinculados al monocultivo de piña en la comunidad de Pital de San Carlos en los años 2012-2013», (Seminario de graduación para optar por el grado de licenciatura en Trabajo Social, Universidad de Costa Rica, 2014), 149, http://www.ts.ucr.ac.cr/binarios/tfglic-sr/tfg-1-sr-2014-03.pdf

${ }^{51}$ Adolfo Sánchez Vázquez, «La cuestión del poder en Marx», Marxismo Crítico, 2011, 7, acceso: 19 de octubre, 2020,

https://marxismocritico.files.wordpress.com/2011/10/la_cuestion_del_poder_en_marx.pdf

52 Adolfo Sánchez Vázquez, «La cuestión...

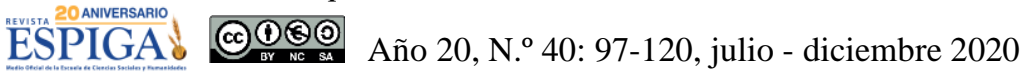


particulares de clase ${ }^{53}$. Entonces, el Estado representa una apariencia «universal» que impide ver que el poder estatal favorece intereses particulares de clase.

Mediando estas ideas, en el país se crearon normas puntuales ligadas al Contrato de Exportación $^{54}$ de la fruta como el Certificado de Abono Tributario ${ }^{55}$ [subsidios del Estado]; la Ley de Zonas Francas, que protege a las piñeras e incluye un conjunto de exoneraciones fiscales que hacen más rentable la actividad para las empresas, pero a su vez da menos tributos para el Estado. También, les protege la Ley de Creación del programa de Reconversión Productiva del sector agropecuario (Ley No.7742), además de otro mecanismo, el Régimen de Admisión Temporal ${ }^{56}$ y el Régimen Devolutivo de Derechos ${ }^{57}$.

Estas medidas incentivaron la producción piñera en la zona atlántica y norte, un monocultivo que requiere mucho territorio, altos volúmenes de insecticidas, pesticidas, abonos y agua. Así, se fue destruyendo la naturaleza, saturando los suelos

${ }^{53}$ Adolfo Sánchez Vázquez, «La cuestión..., 7-8.

${ }^{54}$ Ley 7092, del 21 de abril de 1988, Ley del Impuesto sobre la Renta (La Gaceta N ${ }^{\circ} 96$ del 19 de mayo de 1988), Artículo 66. Se crean los contratos de exportación y de producción para la exportación, como los instrumentos para conceder ventajas y beneficios a las empresas exportadoras de productos no tradicionales no amparadas a tratados de libre comercio, y a las empresas productoras contempladas en el párrafo final del artículo anterior, tales como: a) tarifas portuarias especiales, b) simplificación de procedimientos y trámites, c) créditos bancarios con tasas de interés y plazos de pagos preferenciales.

${ }^{55}$ Ley 7092, del 21 de abril de 1988, Ley del Impuesto...

Artículo 66-c. Los Certificados de Abono Tributario (CAT) serán títulos al portador, libremente negociables y no devengarán intereses. Estos Certificados serán emitidos por el Banco Central de Costa Rica, en moneda nacional y servirán para el pago de los impuestos directos o indirectos cuya recaudación corresponda al Banco Central como cajero del Estado. La solicitud de emisión deberá ser presentada al Centro para la Promoción de las Exportaciones y las Inversiones (***), acompañada de los documentos que al efecto determine el Reglamento de esta Ley, dentro de un plazo máximo de veinticuatro meses contados a partir del reintegro de las divisas. Una vez analizada la documentación presentada, el Centro (**) recomendará, al Banco Central de Costa Rica, las condiciones de emisión de los Certificados. Para efecto del pago de impuestos, estos Certificados podrán utilizarse, después de dieciocho (18) meses contados a partir de la fecha de su emisión...

${ }^{56}$ Ley 7092, del 21 de abril de 1988, Ley del Impuesto (...) El régimen de admisión temporal (Artículo 69). «Se establece un régimen de admisión temporal, mediante el cual se permitirá recibir, dentro del territorio aduanero, con suspensión de toda clase de tributos, las mercancías destinadas al exterior, después de haber sido sometidas a procesos de reparación, reconstrucción, montaje, ensamblaje, incorporación a conjuntos o aparatos de mayor complejidad tecnológica y funcional, o a uso en equipos de transporte y otros fines».

${ }^{57}$ Alexa Obando Sánchez, «El Estado detrás de la piña: El desarrollo de los monocultivos de exportación en la Región Huetar Norte de Costa Rica» (Noveno congreso latinoamericano de ciencia política, 26 de julio de 2017), 11. El Régimen devolutivo de derechos (Artículo 190) «es el régimen aduanero que permite la devolución de las sumas efectivamente pagadas o depositadas a favor del Fisco por concepto de tributos, como consecuencia de la importación definitiva de insumos, envases o embalajes incorporados a productos de exportación...siempre [que esta] se realice dentro del plazo de doce meses contado a partir de la importación de esas mercancías» (91). Como vemos, una regalía más que brinda el Estado (de clase) a los exportadores de piña. Véase: Ley General de Aduanas y su Reglamento (2017). Imprenta Nacional, Editorial Digital. Disponible en: www.imprentanacional.go.cr/editorialdigital/libros/textos\%20jurídicos/ley_aduanas_y_regl amento_pdf

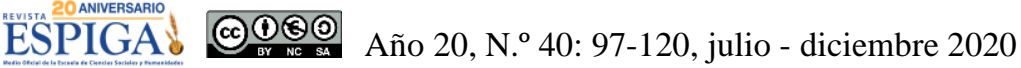


de contaminantes y se inician procesos de infiltración al subsuelo, la contaminación de aguas superficiales y subterráneas que, a su vez, condujo a la contaminación de varios acueductos rurales de la zona atlántica ${ }^{58}$.

Esto ha sido documentado en varias investigaciones, una muy sistemática es la de Felipe Alpízar ${ }^{59}$, de alcance nacional; esta destaca que entre el 2000 y 2010 se dieron 134 conflictos en el país (Alpízar lo denomina «contiendas»), cuyo rasgo distintivo en esa década es una «nueva sensibilidad comunal y ciudadana» y las dos formas de conflictividad son por «protección» y «acceso al agua potable»; este último indicador de conflicto se presentó 47 veces, sumando todas las provincias del país, a excepción de Heredia ${ }^{60}$. En la zona atlántica, en cantones como Guácimo y Siquirres, predomina el conflicto por la «protección».

$\mathrm{Al}$ respecto, una lideresa comunal de Guácimo, entrevistada, comentó que, a partir del 2007 se dieron bastantes luchas en ese cantón por la protección del agua, donde la:

fuente de contaminación son las piñeras (...) en la bajura tenemos problemas (...) toda la parte de la bajura son pozos contaminados (...) Y como son varios pueblos, está Santa María, está la Lucha, está el Limbo, Pueblo Nuevo, Los Ángeles, Santa Rosa, está Carambola; entonces todos esos pueblos son afectados. Podríamos hablar de más de cinco mil personas, fácil ${ }^{61}$.

Otro trabajo, del cual Alpízar ${ }^{62}$ es compilador, titulado: Agua y poder en Costa Rica 1980-2017, plantea que, de 441 «acciones colectivas», en 363 de ellas los principales actores por el agua fueron los «vecinos» $(82,3 \%)$, «grupos ambientales» $(8,6 \%) \mathrm{y}$, en tercer lugar, los «trabajadores» $(2,9 \%)$, entre otros actores ${ }^{63}$.

Destacan los «vecinos» como actor, que en el caso de Guácimo y Siquirres, ha sido muy beligerante y diverso en formas de organización popular; cualitativamente significa que la lucha por el agua está vinculada sensiblemente a la vida cotidiana de las familias. Esto permitió una articulación mayor que dio inicio a un «movimiento socio-ambiental contra la expansión piñera», donde aparece el Foro Emaús y después el Frente Nacional de Sectores Afectados por la Producción Piñera (FRENASAPP), que sirvieron para visibilizar «la problemática socioambiental» causada por la piña ${ }^{64}$.

\footnotetext{
${ }^{58}$ Esteban Acosta Pereira, «La producción piñera en Costa Rica: un análisis integral de sus implicaciones en el cantón de Guácimo, Limón» (Proyecto de graduación para obtener título de Ingeniero Agrónomo, con el grado académico de licenciatura en Ciencias Agrícolas, Universidad EARTH, 2008), 27.

${ }^{59}$ Felipe Alpízar Rodríguez, Poder y participación política en la gestión del agua en Costa Rica (San José: Editorial Arlekín, 2014).

${ }^{60}$ Felipe Alpízar Rodríguez, Poder y participación ..., 220.

${ }^{61}$ Blanca Mejía Molina, comunicación personal, febrero del 2018.

${ }^{62}$ Felipe Alpízar Rodríguez, editor, Agua y poder en Costa Rica 1980-2017 (San José: Centro de Investigación y Estudios Políticos, Vicerrectoría de Investigación, Universidad de Costa Rica, 2019).

${ }^{63}$ Felipe Alpízar Rodríguez, Agua y poder ..., 33.

${ }^{64}$ Gloriana Martínez Sánchez, «La piña nos contaminó el agua: Mujer trabajo y vida cotidiana en comunidades afectadas por la expansión piñera en Costa Rica», Revista Latinoamericana de Geografía 10, n. ${ }^{\circ} 2$ (2019): 7. 
En la zona norte, el conflicto tiene algunos rasgos peculiares entre piñeras, comunidades, actividades productivas tradicionales y Estado; luego de que una investigación, que incluyó un análisis espacial con imágenes satelitales en el 2017, se «encontró 3824 hectáreas de cultivo de piña en Áreas Silvestres Protegidas y 16 385 en humedales ${ }^{65}$.

Este dato, refuerza la opinión de un líder de la ASADA de Pavón de Los Chiles ante la situación del humedal Caño Negro, reservorio de agua que abastece la comunidad por medio de pozos, el cual, algunos estudios de la UCR y la Universidad Nacional, luego de algunas pruebas de laboratorio, detectó que «tres ríos salieron contaminados»; entonces:

(...) hay una situación que tenemos que entender verdad, nosotros dependemos de la Laguna Caño Negro, ese es el eje central, es una cabecera de ríos [...] que le da sostén a un montón de ríos verdad, los humedales y todo eso». Comenta que, por medio de la Unión de Asadas, han obtenido apoyo para cuidar el agua «porque la preocupación de algunos habitantes del cantón de Los Chiles es la contaminación que se ha venido dando de las empresas $^{66}$.

En este conflicto de «intereses» entre diversos actores, hay ganadores y perdedores; estos últimos han activado varias formas de lucha, desde denuncias institucionales, misivas de peticiones, involucrando y haciendo presión a la municipalidad del cantón (Los Chiles), como fue la lucha por imponer una moratoria a las empresas para no sembrar piña durante varios años; visitas y diálogos con autoridades de instituciones estatales para poner en regla a las empresas que irrespetan las leyes ambientales e inspecciones a ríos; incluso una caminata a la Casa Presidencial de Costa Rica durante el gobierno de Luis Guillermo Solís (2014-2018). En la zona atlántica, se llevó el caso de la contaminación de los acueductos de El Cairo y Milano de Siquirres, hasta la Comisión Interamericana de Derechos Humanos, con sede en Washington, luego de varios años de que el agua de consumo humano fuera contaminada con agroquímicos.

Entre una variedad de luchas de ASADAS, comunidades, vecinos, pequeños y medianos productores, indígenas, organizaciones sociales, políticas, ambientales y culturales, en varias zonas geográficas, imbricadas al accionar de un «sujeto colectivo» de movimientos sociales, regionales y nacionales, tales como el ecofeminista, ambientalista, indígena, sindical, estudiantil y académico de universidades públicas, articulado en forma de red al territorio y que conlleva, de una parte, a la «autoconstrucción» de subjetividades, y por la otra, a «determinaciones objetivas en términos de relaciones sociales» e incluyen «relaciones de producción» ${ }^{67}$; que refieren a una lucha con presencia de actores sociales con identidades y «origen social» diverso, convocados, en este caso, por la

\footnotetext{
${ }^{65}$ Resumen Estado de La Nación (2019), 50.

${ }^{66}$ Gerardo Barva, comunicación personal, miembro de la ASADA Pavón de Los Chiles, enero del 2018.

${ }^{67}$ Acosta, Yamandú, «Las nuevas referencias del pensamiento crítico en América Latina. Ética y ampliación de la sociedad civil», Facultad de Humanidades y Ciencias de la Educación, Universidad de la República, Montevideo, Uruguay. 2003, 75.

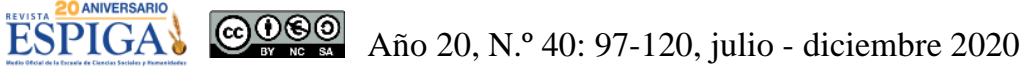


asimetría en las relaciones de poder desigual por acceso al agua frente a los actores empresariales e institucionales.

Implica una lucha «heterogénea» y en distintos niveles (comunitario, socioambiental, económico, jurídico, político y hasta cultural), como lógicas contestarias con intereses diversos y adscripciones clasistas por acceder a una justa redistribución de la renta nacional;las cuales, siguiendo al último Poulantzas, son luchas que tienden «a la modificación de las relaciones de fuerzas en el mismo terreno del Estado» ${ }^{68}$.

\section{La «naturaleza de clase del poder político»}

Sánchez ${ }^{69}$ plantea, asimismo, que el poder político o estatal «no tiene un carácter universal como cree sobre todo Hegel sino particular, de clase». Pero «¿De qué clase?» se pregunta el autor, «De la clase dominante»; es decir, para Marx, el poder del Estado no es para administrar o velar por el interés de toda la sociedad sino «por el de una parte o clase social de ella». Por eso, «la naturaleza del poder reside en su vinculación con la clase a la que sirve administrando sus intereses o "negocios" comunes. No reside, por tanto, en el personal gobernante o los administradores que lo ejercen directamente ${ }^{70}$.

Queda claro que el poder no reside en los que gobiernan o quienes administran directamente las relaciones de poder entre las instituciones del Estado. De ahí que también es un espejismo o, dicho en términos clásicos, una postura «reaccionaria» el imaginar este Estado como un ente externo, por encima de todos, que está preocupado y velando por el «interés general» de todas las clases, incluidas las clases subalternas.

Además, en esta perspectiva analítica, Sánchez ${ }^{71}$ plantea que la:

dominación política está destinada a mantener y reproducir las condiciones generales en que se lleva a cabo su explotación económica, es decir, las relaciones capitalistas de producción (...) [por lo que] no puede darse una contradicción de fondo entre el poder político y la estructura económico social correspondiente [...] la clase que, desde el poder, domina políticamente, no puede volverse contra la dominación económica que ejerce por el lugar que ocupa en las relaciones de producción ${ }^{72}$.

La clase que domina políticamente el Estado es coherente con la dominación que se da en las relaciones sociales de producción en campos piñeros; no hacerlo, sería ir contra su lógica de clase dominante para asegurar la reproducción del capitalismo en la periferia; aunque, como se ha dicho, siguiendo ciertas prácticas no capitalistas que no impide su proceso de acumulación y dominación política.

\footnotetext{
${ }^{68}$ Nicos Poulantzas, Estado...

${ }^{69}$ Adolfo Sánchez Vázquez, «La cuestión...

${ }^{70}$ Adolfo Sánchez Vázquez, «La cuestión..., 8.

${ }^{71}$ Adolfo Sánchez Vázquez, «La cuestión...

72 Adolfo Sánchez Vázquez, «La cuestión..., 8. 


\section{Relaciones de poder y recurso hídrico: una aproximación empírica}

La noción de poder aplicado a las indagaciones empíricas del estudio se resume en tres vías específicas detectadas:

a. Su capacidad para influir la estructura política del Poder Legislativo y en la racionalidad jurídica-administrativa de instituciones del Estado costarricense vinculadas al sector agrícola; particularmente las municipalidades, que otorgan los permisos de explotación en extensos territorios rurales para cosechar la fruta.

Además, otras instituciones estatales a las que acuden las empresas para obtener concesiones sobre acceso al recurso hídrico como la Dirección de Aguas (del MINAE), el Instituto Costarricense de Electricidad y el Ministerio de Agricultura y Ganadería para regular la actividad agrícola. Del lado de los afectados, este poder institucional no se asume pasivamente; al contrario, es resistido con diversas formas de organización y activismo comunitario de vecinos, organizaciones sociales y ambientales; o sea, desde posiciones subalternas de la estructura social. Aquí se trasluce el significado del «poder como relación social» de lucha al incidir en el Estado. Como se ilustra a continuación:

(...) la investigación en Guácimo, Limón, revela cómo el pobre actuar de las instituciones gubernamentales, por ejemplo, el Ministerio de Agricultura y Ganadería (MAG) al regular actividades agrícolas tales como el cultivo de la piña, desencadena una lucha socioambiental que termina por exigir a la municipalidad aplicar regulaciones locales ${ }^{73}$.

En Guácimo, comunidades organizadas han dado grandes luchas. Destaca la resistencia contra el Proyecto Hidroeléctrico Hidroverde, de capital estadounidense, según informantes de la zona ${ }^{74}$, que pretendía encauzar varios ríos. Esta lucha es intensa en acciones y formas de organización entre el 2000 y el 2001; en este periodo hubo muchas protestas de organizaciones ambientales, comunales y fuerzas vivas, incluidos estudiantes de secundaria quienes, en medio de la efervescencia social, decidieron tomarse las instalaciones de la municipalidad durante dos días.

Esto ilustra las relaciones de poder subalternas hacia las instituciones estatales que apoyaban el proyecto, incluida la municipalidad de Guácimo que «había aprobado todos los permisos»; como lo dijo una lideresa: «Fue tan serio que este cantón tuvo que trabajar más de un año explicando barrio por barrio por qué había que sacar a la hidroeléctrica y tuvimos que llegar a un plebiscito... $\rangle^{75}$. Este fue impulsado y ganado por las comunidades.

b. Su capacidad de relaciones («poder social») de influencia y de «fuerza» para imponerse sobre otras fracciones de clase más débiles, desplazándolas en cuanto a

73 Gabriela Cuadrado Quesada, «Gobernanza de aguas subterráneas, conflictos socioambientales y alternativas: Experiencias de Costa Rica», Anuario de Estudios Centroamericanos 43 (2017), 395.

${ }^{74}$ Erlinda Quesada, comunicación personal, febrero del 2018.

${ }^{75}$ Erlinda Quesada, comunicación personal, febrero del 2018.

ESPIGAd c(1) (1) 
su importancia productiva ${ }^{76}$, sea porque estas dedican su producción al mercado local (y este mercado ya no es prioritario) o bien porque su capacidad de relaciones sociales en las estructuras del poder institucional donde se deciden estos negocios son escazas, dada su condición asimétrica de clase. En las municipalidades, el «juego» de poder es determinante, pues allí se deciden las concesiones sobre el uso que se le dará al suelo y, por ende, al agua.

También se aprecia en el poder de otras instituciones, cuya discrepancia denuncia el «divorcio entre lo que las comunidades creen» que es disponibilidad del agua y lo que creen los altos «funcionarios» de acueductos y los mismos

desarrolladores; entonces un desarrollador se va a acueductos (...) donde los mandos más altos y les presentan [un documento] (...) y le ponen, hay disponibilidad hídrica, y resulta que con eso van allá a todos lados y les dan los permisos (...) la disponibilidad dice una cosa [pero] entre los mismos funcionarios de AyA tienen la confusión ${ }^{77}$.

c. Es lo que un entrevistado denomina «el desarrollo informal de muchos empresarios» en las zonas piñeras, donde lo «informal» alude a empresas dedicadas a este monocultivo, pero que no cuentan con los respectivos permisos de la Secretaría Técnica Nacional (SETENA) ${ }^{78}$, los permisos municipales de ubicación, el visto bueno del Sistema Nacional de Áreas de Conservación (SINAC), los permisos de la Dirección de Aguas. Conste que «desde el punto de vista del monocultivo (...) la problemática número uno es el desarrollo informal de muchos empresarios». Con respecto a la municipalidad de Los Chiles, comenta que se trabaja para poner en regla a dichos empresarios ${ }^{79}$.

Un elemento coadyuvante con dicho desarrollo informal es la ausencia de un Plan Regulador para el cantón de Los Chiles; sin esta herramienta de planificación se dificulta la regulación del territorio al gobierno local, que emite:

un uso del suelo de ubicación, donde indica dónde está la propiedad y qué hay en la propiedad (...) para ver si se puede o no desarrollar equis proyecto, obra o construcción. En este caso el permiso de ubicación ha ido más allá, desde mi punto de vista profesional para diferentes desarrollos, hay desarrollos que requieren mayor rigidez y hay otros que no requieren tanta

76 Karina Valverde Salas, Porras Montero, Mariana y Jiménez Corrales Andrés, «La expansión ... 5. «Lo anterior es potenciado por la firma y entrada en vigencia de Tratados de Libre Comercio (TLC) que incentivan un mercado libre de exportación, que ha conducido a un proceso de reconversión agrícola en la Zona Norte-norte, donde se pasó de una producción de granos básicos y ganadería, a una producción en forma de monocultivos, de commodities o «productos postre» para la exportación (principalmente piña y naranja).

${ }^{77}$ Eladio Retana, comunicación personal, Municipalidad de Guácimo, febrero del 2018.

${ }^{78}$ Marylaura Acuña Alvarado y Álvarez Mauricio, s. f. «Situación laboral...

«Entre 2004 y 2015 ...El análisis de los expedientes de la Setena y del trabajo de campo en cantones de esta región (Upala, Los Chiles y Guatuso), concluyó que: i) algunas de las empresas que siembran y procesan piña no cuentan con licencias de viabilidad ambiental, ii) la Setena carece de mecanismos para dar seguimiento en el mediano y largo plazo a los proyectos que sí cuentan con esa autorización...».

79 Harold Vargas, comunicación personal, coordinador de la Unidad Ambiental de la Municipalidad de Los Chiles, febrero del 2018.

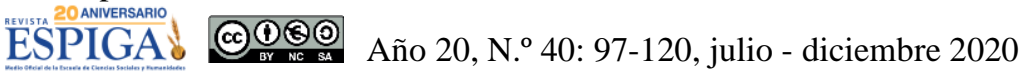


rigidez (...) [además] aquí hay que tratar de convencerlos, alinearlos, informarlos verdad; es que se hacen muchos mitos en la calle, y cuando se habla del Plan Regulador mucha gente se quiere poner los guantes $(\ldots)^{80}$.

Para las empresas que no están a derecho, el plan regulador es inaceptable y lucharán para impedirlo desde el «poder social» que ostentan. Pero ¿Cómo justificar la usurpación de 3824 hectáreas de cultivo de piña en áreas silvestres protegidas, más las 16385 hectáreas en humedales que en el 2019 denunció el informe Estado de la Nación? En Guácimo, el Plan Regulador tiene de por medio obstáculos políticos y no ha sido posible aprobarlo. Aquí persiste el problema del agua contaminada por las piñeras, pero el panorama se ha complejizado con otros actores empresariales que ponen la mirada en los desarrollos de vivienda privados, más otras inversiones de la «economía subterránea», ligada al narcotráfico, que preocupa a algunos de los informantes.

Estas inversiones aumentan el desafío a las comunidades para evitar la contaminación del agua en proyectos que piensan ubicarse donde están las fuentes de agua, relacionado a un nuevo proceso de pérdida de bosque en la parte alta de Guápiles y Guácimo, por una «tala hormiga» mediante una estrategia de destrucción de bosque «de adentro hacia afuera» con propósitos económicos inciertos.

\section{Conclusiones}

El análisis del conjunto de medidas económicas y jurídico-políticas estructurales que tomó el Estado costarricense en décadas pasadas, demuestra que estas favorecieron a la clase dominante, específicamente, su fracción exportadora de productos «no tradicionales»; las cuales, siguiendo a Therborn ${ }^{81}$, da cuenta de la naturaleza clasista del Estado costarricense.

Tales medidas posibilitaron el auge de la producción piñera en el país: que al ser dominante en la zona atlántica y norte, sumado a las malas prácticas productivas, degeneró en procesos sostenidos de contaminación del agua comprobados por estudios de laboratorios de las universidades públicas. Tal escenario, abrió un conflicto socio-ambiental igualmente sostenido con momentos de auge y reflujo en su accionar, pero que ha persistido hasta el presente como conflicto en alguno de sus niveles y formas de lucha.

Aparece, así, un nuevo «sujeto colectivo» diverso y «heterogéneo», que se mueve y lucha desde posiciones de poder subalterno, en medio de las contingencias que el capital impone en dichas zonas y se manifiesta de dos formas: una, a través de la típica lucha capital-trabajo que muchos creen inexistente; la otra, desde una diversidad de sujetos (incluido el comunal) con identidades propias, que los convoca, tanto la sensibilidad por el cuido de la naturaleza incluida el agua, como su capacidad de resistencia frente al poder dominante de empresas e instituciones del Estado, creando una «tensión» que modifica, en cierta dirección, las relaciones de fuerza y poder en el mismo Estado.

${ }^{80}$ Marylaura Acuña Alvarado y Álvarez, Mauricio, s. f. «Situación laboral...

${ }^{81}$ Goran Therborn, ¿Cómo domina...

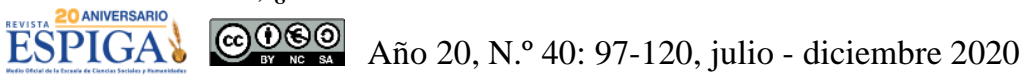


Formato de citación según APA

Bonilla-Bonilla, L. (2020). El conflicto social por el acceso al agua: poder y producción de piña en Costa Rica. Revista Espiga, 20 (40), páginas 97-120

Formato de citación según Chicago-Deusto

Bonilla-Bonilla, Luis. «El conflicto social por el acceso al agua: poder y producción de piña en Costa Rica». Revista Espiga 20, n. 40 (julio-diciembre, 2020): páginas $97-120$

\section{Fuentes consultadas}

Acosta Pereira, Esteban. «La producción piñera en Costa Rica: un análisis integral de sus implicaciones en el cantón de Guácimo, Limón». Proyecto de graduación para obtener el título de Ingeniero Agrónomo con el grado académico de licenciatura en Ciencias Agrícolas, Universidad EARTH. Guácimo, Limón, Costa Rica. 2008.

Acosta, Yamandú. Las nuevas referencias del pensamiento crítico en América Latina. Ética y ampliación de la sociedad civil. Facultad de Humanidades y Ciencias de la Educación, Universidad de la República, Montevideo, Uruguay. 2003.

Acuña Alvarado, Marylaura y Álvarez Mauricio, s. f. «Situación laboral y ambiental de la piñeras [sic.] en la Zona Norte». Kioscos ambientales. https://kioscosambientales.ucr.ac.cr/opinion/46-opinion/1673situaci\%C3\%B3n-laboral-y-ambiental-de-la-pi\%C3\%B1eras-en-la-zonanorte.html

Alpízar Rodríguez, Felipe. Poder y participación política en la gestión del agua en Costa Rica. San José: Editorial Arlekín, 2014.

Alpízar Rodríguez, Felipe, editor. Agua y poder en Costa Rica 1980-2017. San José: Centro de Investigación y Estudios Políticos, Vicerrectoría de Investigación, Universidad de Costa Rica. 2019.

Avendaño Hernández, Karla Rebeca, Ramírez Mora, Karla Patricia y Segura Hernández Ana Gabriela. «Más allá del trabajo asalariado: Implicaciones sociales en el uso del tiempo no remunerado de 
trabajadores y trabajadores vinculados al monocultivo de piña en la comunidad de Pital de San Carlos en los años 2012-2013». Seminario de graduación para optar por el grado de Licenciatura en Trabajo Social. Universidad de Costa Rica, 2014. 149, http://www.ts.ucr.ac.cr/binarios/tfglic-sr/tfg-1-sr-2014-03.pdf

Blanco Obando, Edgar. «Medio ambiente y desarrollo: efectos de las actividades productivas y la legislación ambiental sobre la naturaleza y las condiciones de vida de la población, en la región Chorotega de Costa Rica. 1990-2014». Revista electrónica de Historia, Diálogos, Universidad de Costa Rica, julio-diciembre, San José, Costa Rica. 2016.

Chacón, Vinicio. «Trabajadores de la piña viven clima de explotación laboral». Semanario Universidad, 23 de marzo de 2016. Acceso: 19 de octubre, 2020. https://semanariouniversidad.com/pais/trabajadores-la-pinaviven-clima-explotacion-laboral/

Consejo Nacional de Rectores y Programa Estado de la Nación. Resumen Estado de la Nación. 2019.

Cuadrado Quesada, Gabriela. «Gobernanza de aguas subterráneas, conflictos socioambientales y alternativas: Experiencias de Costa Rica». Anuario de Estudios Centroamericanos 43, (2017): 393-418.

De la Corte Carmona, Jacobo. Schumpeter y la destrucción creativa de instituciones por los innovadores. Madrid: Universidad Pontificia Comillas. 2015.

Esquivel, Francisco. «Costa Rica de la crisis económica al ajuste estructural conservador». En Crisis Económica y ajuste estructural. San José: EUNED, 2007.

Hinkelammert, Franz Josef. El grito del sujeto vivo y corporal frente a la ley del mercado. Buenos Aires: CLACSO/ALAS. 2017.

Gunder Frank, André. Lumpenburguesía: lumpendesarrollo. Dependencia, clase y política en Latinoamérica. Barcelona: Ediciones de bolsillo, 1972.

Ley $\mathrm{N}^{\circ}$ 6955, de 24 de febrero de 1984, Ley para el Equilibrio Financiero del Sector Público (La Gaceta Nº 45 del 2 de marzo de 1984).

Ley 7092, del 21 de abril de 1988, Ley del Impuesto sobre la Renta (La Gaceta $\mathrm{N}^{\circ}$ 96 del 19 de mayo de 1988).

Luxemburgo, Rosa. La acumulación de capital. S. d.: Ediciones Sedov Germinal, 1913.

Martínez Sánchez, Gloriana. «La piña nos contaminó el agua: Mujer trabajo y vida cotidiana en comunidades afectadas por la expansión piñera en Costa Rica», Revista Latinoamericana de Geografía 10, n. ${ }^{\circ} 2$ (2019). 
Obando Sánchez, Alexa. «El Estado detrás de la piña: El desarrollo de los monocultivos de exportación en la Región Huetar Norte de Costa Rica». Noveno congreso latinoamericano de ciencia política, $26 \mathrm{de}$ julio de 2017.

Poulantzas, Nicos. Estado, poder y socialismo. Ciudad de México: Siglo XXI Editores, 1987.

Rovira Mas, Jorge. Costa Rica en los años 80. San José: Editorial Porvenir, 1988.

Sánchez Vázquez, Adolfo. «La cuestión del poder en Marx». Marxismo Crítico, 2011.7.https://marxismocritico.files.wordpress.com/2011/10/la_cues tion_del_poder_en_marx.pdf

Socialismo Hoy. «Piñeras: Tres huelgas en menos de una semana en Zona Norte». 18 de enero de 2019. http://socialismohoy.com/pineras-3-huelgasmenos-semana-zona-norte/

Taylor, Stephen John y Bogdan, Robert. Introducción a los métodos cualitativos de investigación. Buenos Aires: PAIDOS, 1987.

Therborn, Goran. ¿Cómo domina la clase dominante? Aparatos de Estado y poder estatal en el feudalismo, el capitalismo y el socialismo. Ciudad de México: Editorial Siglo XXI, 1987.

Tobón Sanín, Gilberto. «La obra de Nicos Paulantzas y la teoría marxista del derecho y la política», Revista Jurídica Mario Alario D'Filippo 3, n. ${ }^{\circ} 1$ (2011): 36-58.

Valverde Salas, Karina, Porras Montero, Mariana y Jiménez Corrales Andrés, «La expansión por omisión: Territorios piñeros en los cantones Los Chiles, Upala y Guatuso, Costa Rica (2004-2015)». Vigésimosegundo Informe Estado de la Nación en Desarrollo Humano Sostenible, 2018.

Vargas Solís, Luis Paulino. «El proyecto histórico neoliberal en Costa Rica (19482015): devenir histórico y crisis». Revista Rupturas 6, n. ${ }^{\circ} 1$ (2016).

Zúñiga Ramírez, César. «Reforma del Estado en Costa Rica y transformaciones institucionales durante la administración Arias Sánchez (19861990)». Revista de Ciencias Sociales 81 (1998), 22. 